Vol.01/ No. 02

Pages: 97- 109

https://www.irojournals.com/jucct/

DOI: https://doi.org/10.36548/jucct.2019.2.004

\title{
MULTI-OBJECTIVE OPTIMIZATION ALGORITHM FOR POWER MANAGEMENT IN COGNITIVE RADIO NETWORKS
}

\author{
Dr. Wang Haoxiang, \\ Director and lead executive faculty member, \\ GoPerception Laboratory, NY, USA \\ Email id: hw496@goperception.com
}

\begin{abstract}
The cognitive radio networks is an adaptive and intelligent radio network that is capable of automatically identifying the available channels in the spectrum that is wireless. Cognitive radios modify the parameters supporting the conveyance according to the needs of communication to enhance the operating radio behavior and avail a concurrent communication within the allotted spectrum band at one location. To improvise the parameter configuration the intelligent optimization techniques are been followed nowadays. The paper puts forth a multi-objective optimization algorithm (MO-OPA) for the power management in the cognitive radio networks. The proposed method utilizes the hybridized evolutionary algorithm to reduce the power consumption by minimizing the delay in the communication, intervention and the error rate of the packets. The validation of the proposed method is done to using the network simulator-2 to evince the capabilities of the proposed MO-OPA.
\end{abstract}

Keywords: Cognitive Radio Networks, Multi Objective Optimization, Power Management, Evolutionary Algorithm, Minimized Delay, and Error Rates in the Packet.

\section{INTRODUCTION}

The communication needs that are growing at rapid pace day by day are in turn increasing the demands of the wireless communications causing a shortage in the spectrum band. This causes the researchers to identify the novel methods and procedures in communication to enhance it capability, by enabling it to adapt to the changing demands on the spectrum and improve its efficiency in communication.

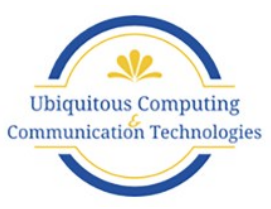


Journal of Ubiquitous Computing and Communication Technologies (UCCT) (2019)

Vol.01/ No. 02

Pages: 97- 109

https://www.irojournals.com/jucct/

DOI: https://doi.org/10.36548/jucct.2019.2.004

The breach between the communication demands and the available spectrum has created an impending spectrum crisis as the demands of the smart phones overwhelm the capacity of the wireless communication. The actual problem is the lack of spectrum availability for the data carriers. The growing mobile devices usage requires a huge amount of spectrum that is required for the broad band use in the future.

To overcome the problem of the spectrum demand the Cognitive Radio were put forward. The Cognitive radio is defined as the "radio system that employs technology that allows obtaining knowledge of its operational and the geographical environment, established policies and its internal state. It dynamically and autonomously adjusts its operational parameters and protocols according to its obtained knowledge in order to achieve predefined objectives and to learn from the results obtained"

The prominent example of the opportunistic spectrum access is the reuse of the licensed spectrum by the secondary users without interfering, the operations of the primary users. The fig. 1 below shows the reuse of the licensed spectrum by the unlicensed users.

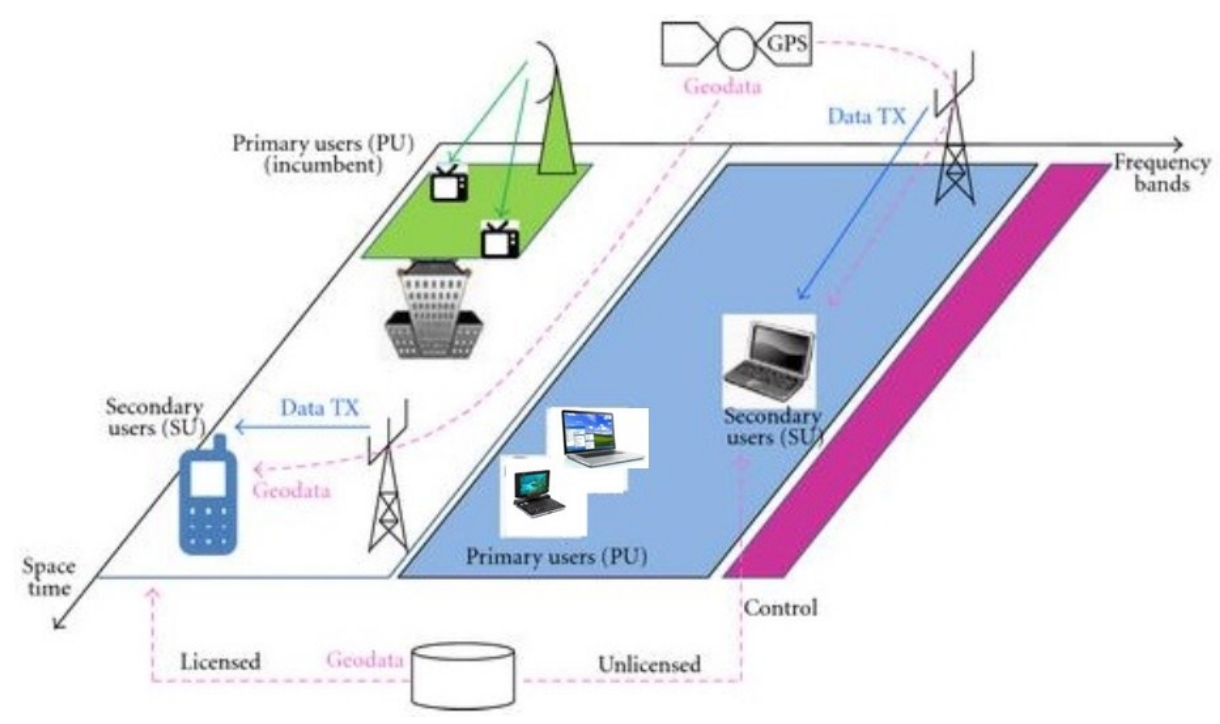

Fig.1 Spectrum Reuse of Cognitive Radios[4]

98

ISSN: 2582-337X (online) 
Journal of Ubiquitous Computing and Communication Technologies (UCCT) (2019)

Vol.01/ No. 02

Pages: 97- 109

https://www.irojournals.com/jucct/

DOI: https://doi.org/10.36548/jucct.2019.2.004

Cognitive radio being an adaptive and an intelligent radio network to automatically identify the available channels configures the parameters using the optimization technique to improvise the operating radio behavior and avail a concurrent communication within the allotted spectrum band at a location.

The proposed methodology in the paper provides the optimization in the power utilization of the cognitive radio network using the evolutionary algorithms, thereby reducing the delay in the communication, intervention and the error rate of the packets.

The Remaining paper is organized with the related works in the section 2, proposed multi-objective optimization in the section. 3 and results evaluation in section 4 and conclusion in section 5

\section{RELATED WORKS}

The authors "Darney, P. Ebby, and I. Jeena Jacob et al [1] have put forward the "performance enhancements of cognitive radio networks utilizing the fuzzy logic" proposing the reuse of the spectrum bandwidth for the unlicensed users without affecting the operations of the licensed primary users. Mitola, Joseph et al [2] put forth the cognitive radio as the promising technology to enhance the utilization of the spectrum and the efficiency in the network. In her paper [3] she has put forth the "foundations, technological tradeoffs and the architecture implications of the Software radio architecture" the fig. 2 below provides the structure Cognitive radio network

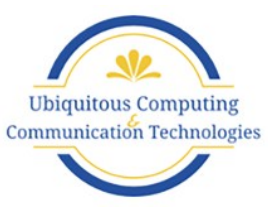

ISSN: 2582-337X (online) 
Journal of Ubiquitous Computing and Communication Technologies (UCCT) (2019)

Vol.01/ No. 02

Pages: 97- 109

https://www.irojournals.com/jucct/

DOI: https://doi.org/10.36548/jucct.2019.2.004

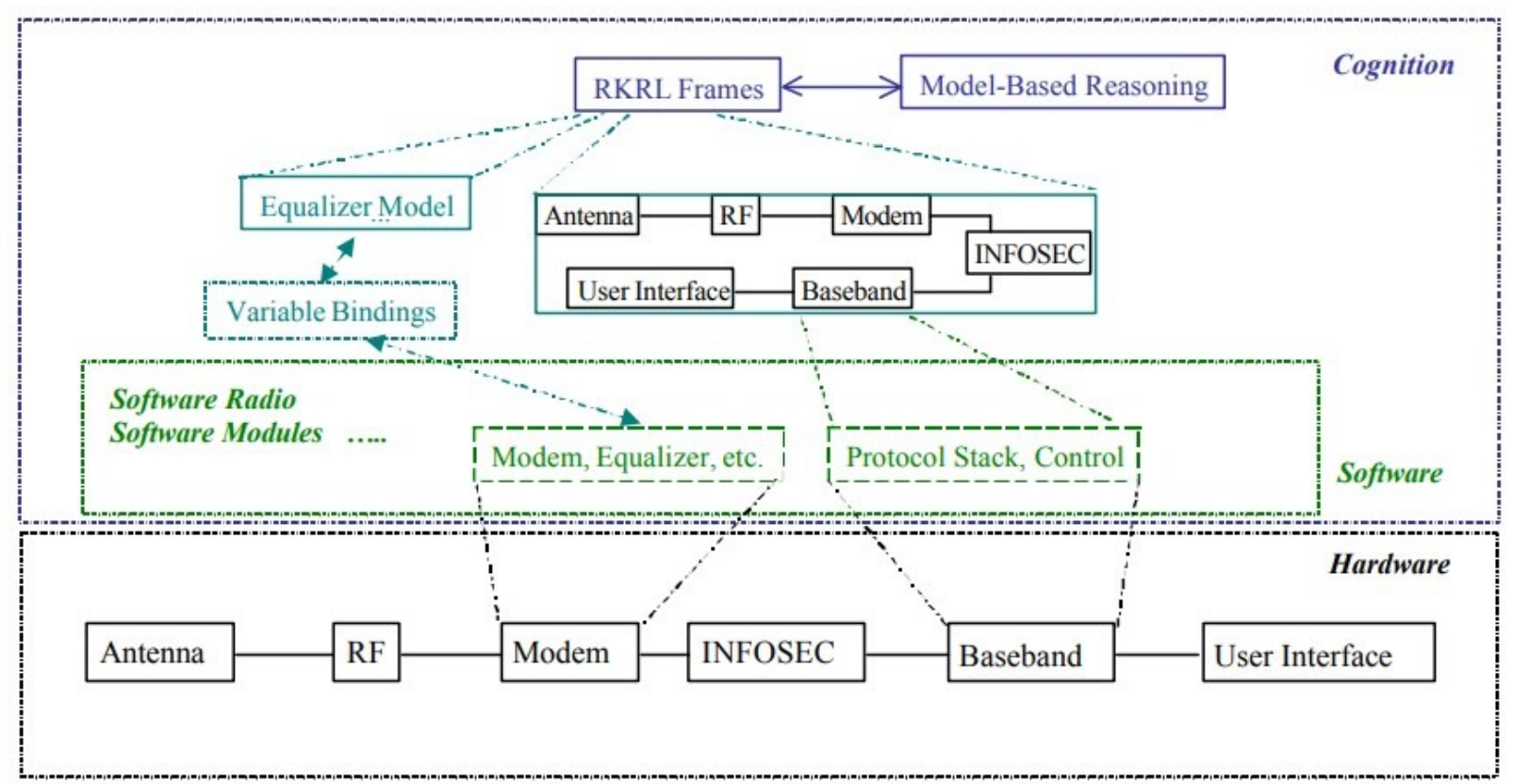

Fig.2 Cognitive Radio Network

The author Brodersen, Robert et al [4] explains the "virtual licensed spectrum approach for the cognitive radio networks" Jondral, Friedrich $\mathrm{K}$ et al [5] proposes the evolution and the basics of the cognitive software defined radio. Amanna, Ashwin, and Jeffrey H. Reed et al [6] elaborates the survey of the "Cognitive radio architectures"

The author Thomas, Ryan W et al [7] proposes the "software defined radio and adaptive wireless system for the cognitive networks" and Da Silva, et al [8] presents the "Distributed spectrum sensing for cognitive radio systems." Sathesh et al [9] details the multi objective optimization followed in the wireless communication to optimize the resource utilization. Rahimunnisa, et al [10] proposes the hybridized genetic and the simulated annealing to achieve the performance optimization in the wireless adhoc networks.

Nguyen, Van Tam, et al [11] provides the over view and the challenges of the cognitive radio. Raj, Jennifer S. " et al [12] presents the "a comprehensive survey on the computational intelligence techniques and its applications." Pandian, M. Durai. et al [13] provides the "enhanced network performance and mobility management of IoT multi 100

ISSN: 2582-337X (online)

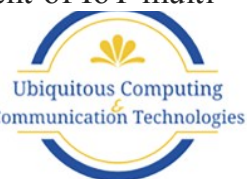


Journal of Ubiquitous Computing and Communication Technologies (UCCT) (2019)

Vol.01/ No. 02

Pages: 97- 109

https://www.irojournals.com/jucct/

DOI: https://doi.org/10.36548/jucct.2019.2.004

networks." Bashar, Abul et al [14] puts forth the "Survey on Evolving Deep Learning Neural Network Architectures." Pandian. et al [15] provides the "Enhanced Network Selection and Handover Schema for Heterogeneous Wireless Networks." Valanarasu, et al [16] provides the "comprehensive survey of wireless cognitive and 5g networks." and Joseph, S. Iwin Thanakumar et al [17] presents the "survey of data mining algorithm's for intelligent computing system." Haykin, Simon et al presents the "Cognitive dynamic systems"

\section{PROPOSED WORK}

The Cognitive Radio relies on the principles of on the fly and the environment aware computing. The wireless applications that are related to the cognitive communication require a standard ontology to have an efficient information sharing. This necessitates the expert knowledge in the cognitive radio and therefore embeds the machine learning technique in the paradigm to enhance the robustness of the swiftly changing external environments. The machine learning techniques extensively used in the cognitive radios are the basically based on the supervise and the unsupervised technologies and most of the research so far have implemented the machine learning process to gain the knowledge about the bottle necks in the engineering and the limited flexibilities in the software. The prevailing methods have utilized the genetic algorithm in optimizing the performance of the cognitive radio networks

The proposed method in order to have a better performance optimization does a multi- objective optimization utilizing the hybridized evolutionary algorithm (Genetic algorithm- simulated annealing - GASA) to manage the power utilization in the cognitive networks by minimizing the delay, the error rate in the packets and the noises or the intervention found in the communication.

The multi-objective optimization is mathematically described as the shown in the equation (1) below

$$
\min / \max (I)=\left\{F_{f}(j), F_{f 1}(j), \ldots F_{f n}(j)\right\}
$$

Where $F_{f}$ denotes the objective function to be optimized for the $j$ set of parameters in the $I$ dimensions for ' $n$ ' number of objective function. The paper aims in reducing the power utilization in the cognitive radio network by

\section{1}

ISSN: 2582-337X (online)

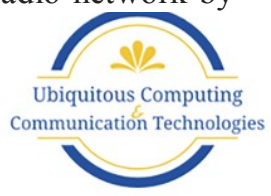


Journal of Ubiquitous Computing and Communication Technologies (UCCT) (2019)

Vol.01/ No. 02

Pages: 97- 109

https://www.irojournals.com/jucct/

DOI: https://doi.org/10.36548/jucct.2019.2.004

reducing the delay in the communication, the error rate in the packet and the intervention in the form of noises, etc. so the main objective functions to be considered are, power utilization, delay, bit error rate, interventions in the communication.

\subsection{MULTI-OBJECTIVE FUNCTIONS TO BE OPTIMIZED}

(a).Delay Minimization ( $\boldsymbol{D e l a} \boldsymbol{y}_{\boldsymbol{F} f}$ ): The wireless applications are always delay sensitive, more over the delay in the communication also remains as the main cause for the power consumption so it is necessary to optimize the delay in the network communication so as to bring down the power utilization of the network, the equation (2) framed used in optimizing the delay of the cognitive network.

$$
\operatorname{Delay}_{F f}=f r_{x} *\left(^{\log _{2} M_{\text {max }}} / f r_{x_{\min }} * \sum_{x=1}^{N_{n}} \log _{2} m_{x}\right)
$$

Where $f r_{x}$ is the dimension of the sub-carrier $x$,

(b).Bit Error Rate Minimization $\left(\boldsymbol{B} E \boldsymbol{R}_{\boldsymbol{F f}}\right)$ : The eminence of the each connection is enumerated to gain information about the error occurrences in the links based on the number of errors occurred link eminence is determined (link $k_{\text {quality }}$ ), the rate of the bit errors depends on many transmission parameters such as the power required for the transmission, the bandwidth utilized, the noise power, the modulation index and the type of the modulation, symbol rate and the number of the hops taken along with the size of the contention window.

$$
B E R_{F f}=\left\{\begin{array}{cc}
1-\frac{\log _{10}\left(\frac{1}{2}\right)}{\log _{10} \text { window }_{\text {size }}} & \text { for } B E R_{\text {actual }} \leq B E R \leq B E R_{\text {tolerable }} \\
1 & \text { for } B E R<B E R_{\text {actual }} \\
0 & \text { for } B E R>B E R_{\text {tolerable }}
\end{array}\right.
$$

ISSN: 2582-337X (online)

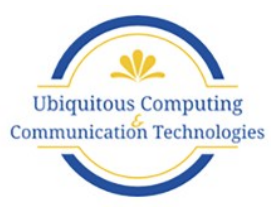


Journal of Ubiquitous Computing and Communication Technologies (UCCT) (2019)

Vol.01/ No. 02

Pages: 97- 109

https://www.irojournals.com/jucct/

DOI: https://doi.org/10.36548/jucct.2019.2.004

The equation 3 help in optimizing the error occurrences in the link so as to reduce the transmission power utilization.

(c).Minimization in intervention (intervention $\boldsymbol{F f}_{\text {) }}$ : The spectrum sharing is often affected by the inference that remains as a major difficulty in the cognitive radio communication this affects not only the power for the transmission (Tpower) also many other parameters that are constituents of the transmission. The following equation (4) enables to reduce the interference in the communication.

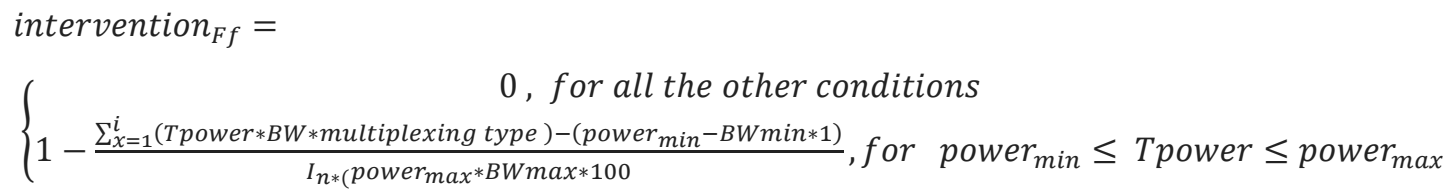

\subsection{PROPOSED MULTIOBJECTIVE OPTIMIZATION ALGORITHM}

The objectives functions specified are interdependent so the proposed method utilizes the GASA [10] (genetic algorithm with simulated annealing) to optimize the parameters of the cognitive network so as to minimize the delay, in the communication, error occurrence and the intervention in the communication in turn to minimize the power utilization in the transmission. The algorithm explaining the multi-objective optimization is presented below in the fig . 3 and the table .1 presents the parameters taken into considerations and their abbreviations.

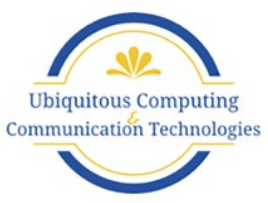

ISSN: 2582-337X (online) 
Journal of Ubiquitous Computing and Communication Technologies (UCCT) (2019)

Vol.01/ No. 02

Pages: 97- 109

https://www.irojournals.com/jucct/

DOI: https://doi.org/10.36548/jucct.2019.2.004

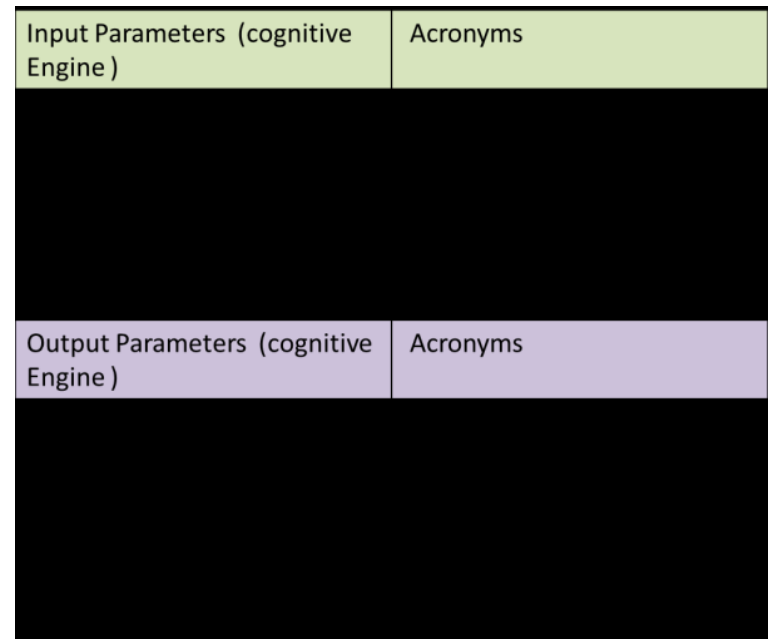

Table.1 Transmission Parameters

ISSN: 2582-337X (online) 
Journal of Ubiquitous Computing and Communication Technologies (UCCT) (2019)

Vol.01/ No. 02

Pages: 97- 109

https://www.irojournals.com/jucct/

DOI: https://doi.org/10.36548/jucct.2019.2.004

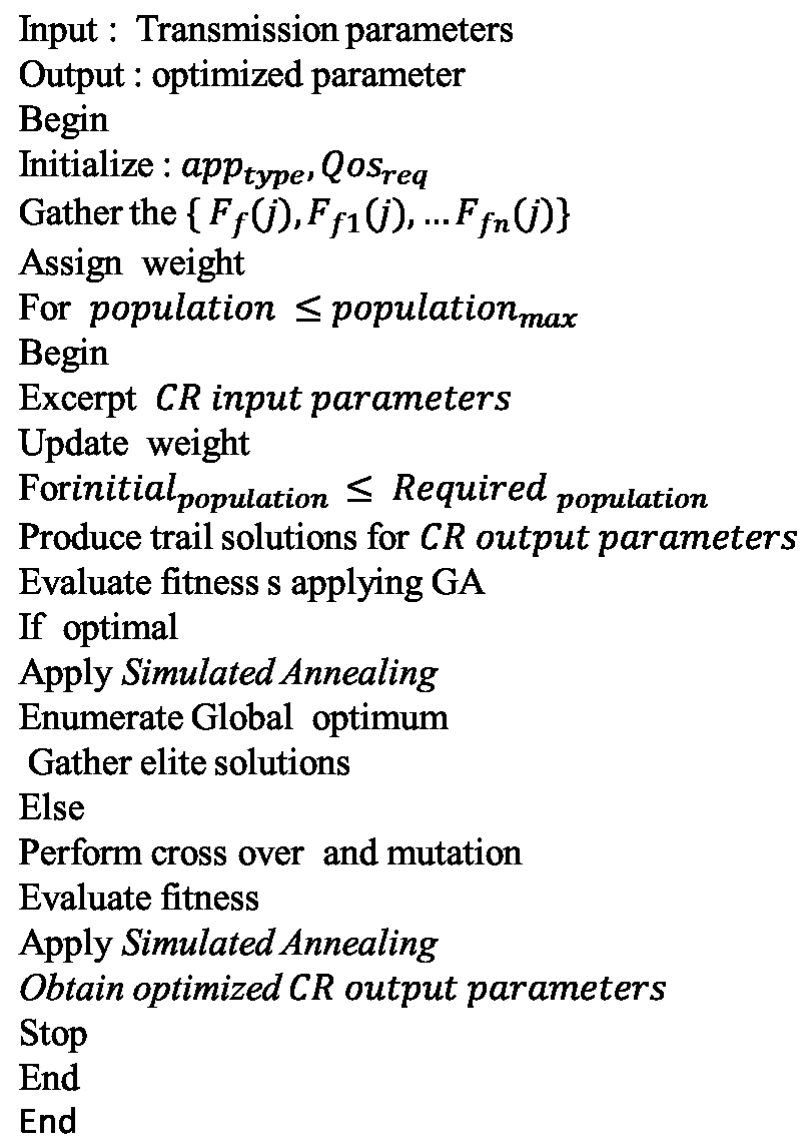

Fig.3 Proposed Multi-Objective Algorithm

\section{RESULTS EVALUATION}

The Network simulator-2 is utilized to validate the proposed algorithm that employs the fittest transmission constraint to optimize the delay of the transmission, error rate and the interference. The results are obtained in terms of the delay, packet error rate and the power consumption. The result of the proposed method is compared with the existing methods. The details of the simulation parameters engaged in the transmission are listed below in the table. 2

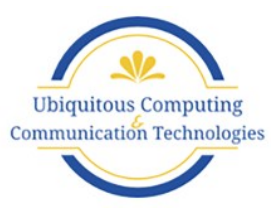

ISSN: 2582-337X (online) 
Journal of Ubiquitous Computing and Communication Technologies (UCCT) (2019)

Vol.01/ No. 02

Pages: 97- 109

https://www.irojournals.com/jucct/

DOI: https://doi.org/10.36548/jucct.2019.2.004

\begin{tabular}{|c|c|}
\hline Parameter & Range \\
\hline Simulation Tool & Network simulator -2 \\
\hline Simulation time & 2000 seconds \\
\hline Bandwidth & 2 to $128 \mathrm{MHz}$ \\
\hline Population size & 100 \\
\hline Mutation rate & .5 \\
\hline Cross over rate & $5-7$ \\
\hline
\end{tabular}

Table.2 Simulation Parameters

The fig .4 below shows the delay minimization achieved by the proposed method, for the various communication nodes with at different simulation time and compare with the prevailing methods that are based on the PSO and the ACO,

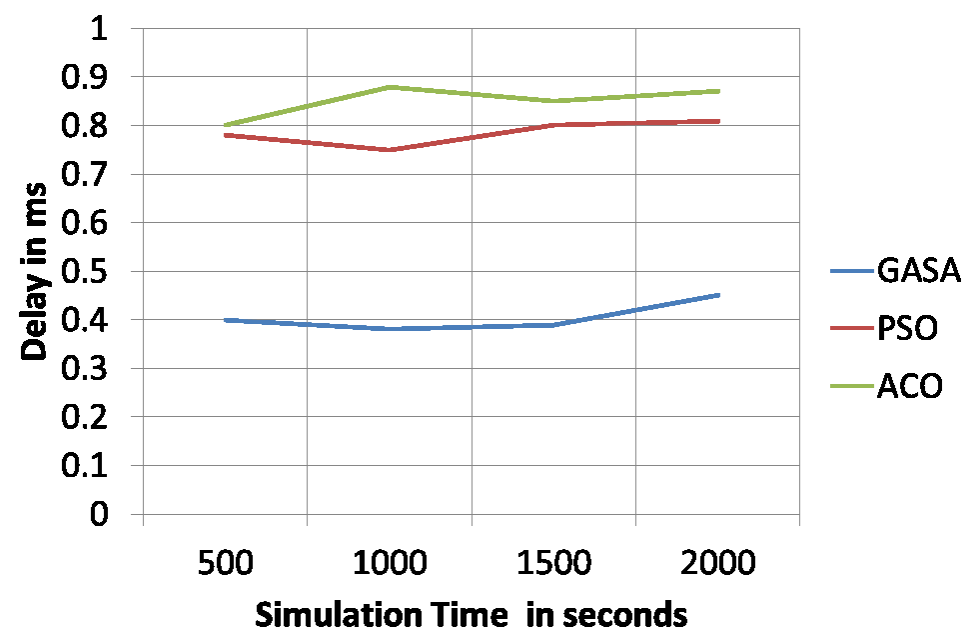

ISSN: 2582-337X (online) 
Journal of Ubiquitous Computing and Communication Technologies (UCCT) (2019)

Vol.01/ No. 02

Pages: 97- 109

https://www.irojournals.com/jucct/

DOI: https://doi.org/10.36548/jucct.2019.2.004

Fig.4 Delay Achieved

The figure. 5 below shows the throughput achieved by the proposed method and its comparison with the prevailing methods based on the ACO and the PSO, the throughput improvement achieved shows the reduced error occurrence in the connection and the communication.

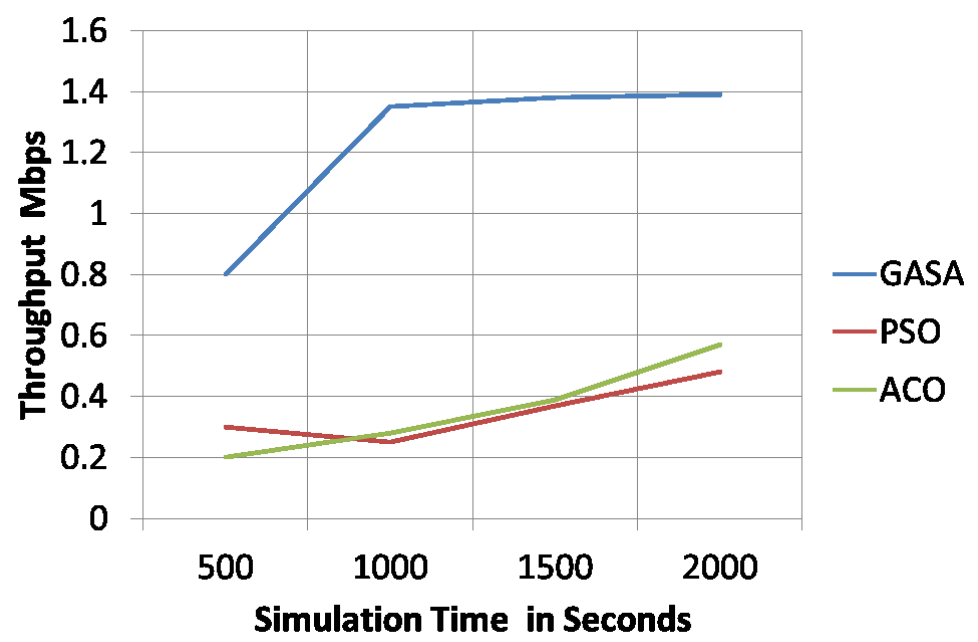

Fig, 5 Throughput

The fig .6 presents the power utilized for the communication. The optimized parameter utilized in the communication of the network enables to reduce the delay, interference, error occurrences and thereby reduce the power utilized in the conveyance.

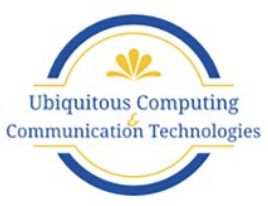

ISSN: 2582-337X (online) 
Journal of Ubiquitous Computing and Communication Technologies (UCCT) (2019)

Vol.01/ No. 02

Pages: 97- 109

https://www.irojournals.com/jucct/

DOI: https://doi.org/10.36548/jucct.2019.2.004

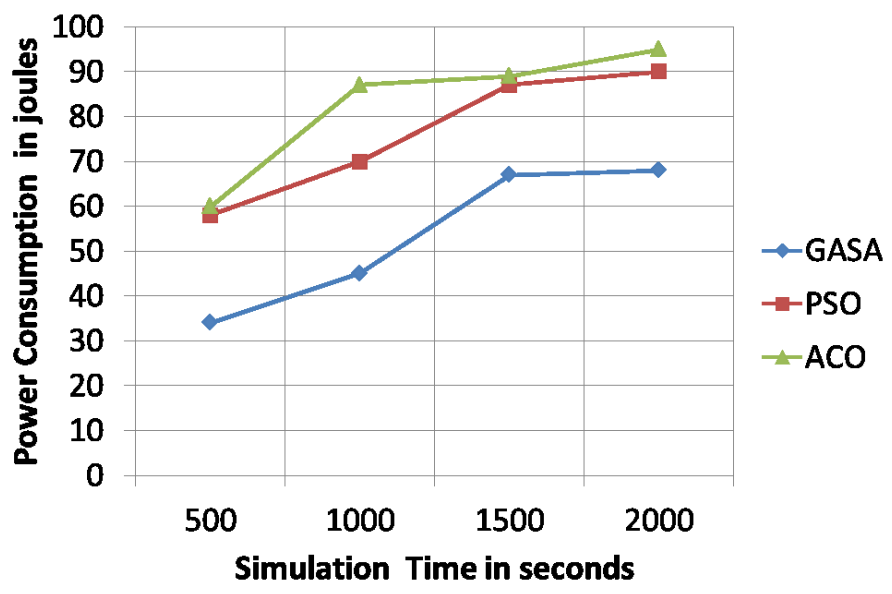

Fig.6 Power Utilization

\section{CONCLUSION}

The paper puts forth the power management in the cognitive -radio networks by optimizing the parameters used in the conveyance applying the GASA and reducing the delay in the communication, the errors occurrences in the connection and minimizing the interferences in the communication. The optimized parameters also reduce the power utilization in the transmission. The simulation results obtained shows that the proposed method provides a $25 \%$ better power utilization compared to the PSO and the $38 \%$ better power utilization than the ACO. In future the paper would proceed with the effective decision making on the resource management of the network applying the Evolutionary algorithm.

\section{References}

[1] Darney, P. Ebby, and I. Jeena Jacob. "PERFORMANCE ENHANCEMENTS OF COGNITIVE RADIO NETWORKS USING THE IMPROVED FUZZY LOGIC." Journal of Soft Computing Paradigm (JSCP) 1, no. 02 (2019): 57-68.

[2] Mitola, Joseph. "Cognitive radio." PhD diss., Institutionen för teleinformatik, 2000. 108

ISSN: 2582-337X (online)

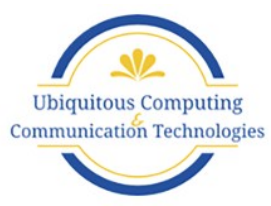


Journal of Ubiquitous Computing and Communication Technologies (UCCT) (2019)

Vol.01/ No. 02

Pages: 97- 109

https://www.irojournals.com/jucct/

DOI: https://doi.org/10.36548/jucct.2019.2.004

[3] MITOLA III, Joseph. "Software radio architecture evolution: Foundations, technology tradeoffs, and architecture implications." IEICE transactions on communications 83, no. 6 (2000): 1165-1173.

[4] Brodersen, Robert W., Adam Wolisz, Danijela Cabric, Shridhar Mubaraq Mishra, and Daniel Willkomm. "Corvus: a cognitive radio approach for usage of virtual unlicensed spectrum." Berkeley Wireless Research Center (BWRC) White paper 18 (2004).

[5] Jondral, Friedrich K. "Software-defined radio: basics and evolution to cognitive radio." EURASIP journal on wireless communications and networking 2005, no. 3 (2005): 275-283.

[6] Amanna, Ashwin, and Jeffrey H. Reed. "Survey of cognitive radio architectures." In Proceedings of the IEEE SoutheastCon 2010 (SoutheastCon), pp. 292-297. IEEE, 2010.

[7] Thomas, Ryan W., Daniel H. Friend, Luiz A. DaSilva, and Allen B. MacKenzie. "Cognitive networks." In Cognitive radio, software defined radio, and adaptive wireless systems, pp. 17-41. Springer, Dordrecht, 2007.

[8] Da Silva, Claudio RCM, Brian Choi, and Kyouwoong Kim. "Distributed spectrum sensing for cognitive radio systems." In 2007 Information Theory and Applications Workshop, pp. 120-123. IEEE, 2007.

[9] Sathesh, A. "OPTIMIZED MULTI-OBJECTIVE ROUTING FOR WIRELESS COMMUNICATION WITH LOAD BALANCING." Journal of trends in Computer Science and Smart technology (TCSST) 1, no. 02 (2019): 106-120.

[10] Rahimunnisa, K. "HYBRIDIZED GENETIC-SIMULATED ANNEALING ALGORITHM FOR PERFORMANCE OPTIMIZATION IN WIRELESS ADHOC NETWORK." Journal of Soft Computing Paradigm (JSCP) 1, no. 01 (2019): 1-13..

[11] Nguyen, Van Tam, Frederic Villain, and Yann Le Guillou. "Cognitive radio RF: overview and challenges." VLSI Design 2012 (2012): 1.

[12] Raj, Jennifer S. "A COMPREHENSIVE SURVEY ON THE COMPUTATIONAL INTELLIGENCE TECHNIQUES AND ITS APPLICATIONS." Journal of ISMAC 1, no. 03 (2019): 147-159.

[13] Pandian, M. Durai. "ENHANCED NETWORK PERFORMANCE AND MOBILITY MANAGEMENT OF IOT MULTI NETWORKS." Journal of trends in Computer Science and Smart technology (TCSST) 1, no. 02 (2019): 95-105.

[14] Bashar, Abul. "SURVEY ON EVOLVING DEEP LEARNING NEURAL NETWORK ARCHITECTURES." Journal of Artificial Intelligence 1, no. 02 (2019): 73-82.

[15] Pandian, M. Durai. "ENHANCED NETWORK SELECTION AND HANDOVER SCHEMA FOR HETEROGENEOUS WIRELESS NETWORKS." Journal of ISMAC 1, no. 03 (2019): 160-171.

ISSN: 2582-337X (online)

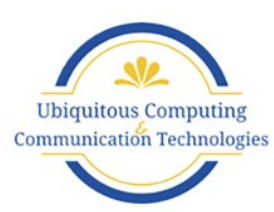


Journal of Ubiquitous Computing and Communication Technologies (UCCT) (2019)

Vol.01/ No. 02

Pages: 97- 109

https://www.irojournals.com/jucct/

DOI: https://doi.org/10.36548/jucct.2019.2.004

[16] Valanarasu, Mr R., and A. Christy. "COMPREHENSIVE SURVEY OF WIRELESS COGNITIVE AND 5G NETWORKS." Journal of Ubiquitous Computing and Communication Technologies (UCCT) (2019): 23-32.

[17] Joseph, S. Iwin Thanakumar. "SURVEY OF DATA MINING ALGORITHM'S FOR INTELLIGENT COMPUTING SYSTEM." Journal of trends in Computer Science and Smart technology (TCSST) 1, no. 01 (2019): 14-24.

[18] Haykin, Simon. "Cognitive dynamic systems." In 2007 IEEE International Conference on Acoustics, Speech and Signal Processing-ICASSP'07, vol. 4, pp. IV-1369. IEEE, 2007. 